\title{
RANCANG BANGUN EXTERNAL ELECTROMAGNETIC RETARDERS SYSTEM PADA MOTOR 1 PHASA
}

\author{
Bima Dicky Anugrah Dewantara, Saiful Manan \\ Program Studi Diploma III Teknik Elektro \\ Sekolah Vokasi Universitas Diponegoro
}

\begin{abstract}
Bima Dicky Anugrah Dewantara, Saiful Manan, in this paper explain that Electromagnetic retarders are generally known as electromagnetic inhibitors or brakes, the braking system eliminates most braking mechanics, thereby reducing conventional braking systems. Safety requirements and safety systems are developed and become a focal point of an equipment. Electromagnetic brakes are a safety component with a control system that is easy to control. With this electromagnetic brake, it will reduce maintenance costs, because it only requires a factor of electricity to be able to move it. The braking system uses electromagnetic forces to slow down a movement, which is generally a shaft motion. A dish with non-ferromagnetic metal material is attached to a rotating shaft. The disk is flanked by the side of the stator in the form of an electromagnetic coil system that can generate a magnetic field from electricity. Electric current generates a magnetic field in the coil. And the metal plate that cuts the magnetic field will cause eddy currents on the disk itself. This eddy current will generate a magnetic field whose direction is opposite to the previous magnetic field, thus inhibiting the rotary motion of the shaft. In designing, experimenting and making an External Electromagnetic Retarders System Design on 1 Phase Motor, use the NE 555 IC as the control duty cycle. So that the relationship between braking current and braking time is inversely proportional if the higher the current, the shorter the time it takes for the rotor to stop. And the relationship between braking current and motor current is directly proportional, by increasing the braking current will increase the load on the motor causing the motor current to increase.
\end{abstract}

Keywords: Electromagnetic Retarders, Electromagnetic Brakes, Eddy Flow Effect

\section{PENDAHULUAN \\ Latar Belakang}

Pengereman pada motor induksi pada umumnya masih menggunakan metode konvensional yang dapat menyebabkan kerugian mekanis sehingga berpengaruh pada umur motor induksi. Selain pengereman yang masih menggunakan cara konvensional. Salah satu yang dapat dikontrol adalah sistem pengereman pada motor induksi yang banyak terdapat pada dunia industri khususnya pada mesin-mesin yang menggunakan motor induksi sebagai penggeraknya. Motor induksi sendiri dapat terhenti dengan adanya geseran yang terjadi, tetapi tentu saja hal ini membutuhkan waktu yang lama, untuk itu diperlukan pengereman supaya dapat menghentikan motor dengan waktu yang relatif singkat. Selama ini pengereman yang berlangsung di luar system motor biasanya mengunakan pengereman mekanik, dengan pengereman mekanik dapat menimbulkan berbagai hal, seperti gangguan suara yang di timbulkan, perlunya perawatan atau pengantian secara berkala komponen pengereman karena habis terkikis dari gesekan mekanis yang di timbulkan. Dengan adanya perawatan berkala maka memperlukan biaya. Tujuan penelitian ini adalah memanfaatkan arus eddy untuk menghasilkan gaya putar yang dapat diatur sehingga diciptakan sebuah mekanisme rem electromagnet. Penelitian ini menggunakan motor 1 fasa $220 \mathrm{VAC}$.

\section{TINJAUAN PUSTAKA Arus eddy}

Arus eddy merupakan arus listrik yang diinduksikan kedalam konduktor dengan mengubah medan magnet konduktor tersebut. Sirkulasi pusaran arus ini memiliki induktansi dan medan magnet. Medan ini dapat menyebabkan tolakan, tarikan, dorongan, dan efek pemanasan.

Arus eddy terbentuk ketika terjadi perubahan letak konduktor dalam sebuah medan magnet. Konduktor yang bergerak dalam sebuah medan magnet yang tetap ataupun megan magnet yang berubah disekitar konduktor yang diam, keduanya menyebabkan arus eddy terbentuk dalam konduktor tersebut. Arus eddy menghasilkan losses resistif yang dapat mengubah beberapa bentuk energi, seperti energi kinetik menjadi panas.

\section{Medan Magnet pada Solenoida}

Sebuah kawat dibentuk seperti spiral yang selanjutnya disebut kumparan, apabila dialiri arus listrik maka akan berfungsi seperti magnet batang.

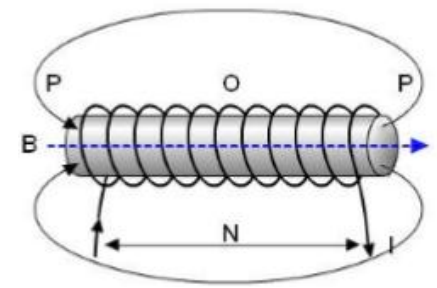

Gambar 1. Solenoida 
Besarnya medan magnet disumbu pusat (titik O) solenoida dapat dihitung :

Dimana :

$$
B_{0}=\frac{\mu_{0} \cdot I . N}{L}
$$

Bo $=$ medan magnet pada pusat solenoid $(\mathrm{T})$

Mo $=$ permeabilitas ruang hampa $=4 \Pi \cdot 10-7$

$\mathrm{Wb} / \mathrm{Am}$

$\mathrm{I}=$ kuat arus listrik dalam ampere (A)

$\mathrm{N}=$ jumlah lilitan dalam solenoida

$\mathrm{L}=$ panjang solenoida dalam meter $(\mathrm{m})$

Besarnya medan magnet di ujung solenoida (titik P) dapat dihitung:

$$
B_{p}=1 / 2 \frac{\mu_{0} \cdot I \cdot N}{L}
$$

Dimana :

$\mathrm{BP}=$ Medan magnet diujung solenoida $(\mathrm{T})$

$\mathrm{N}=$ jumlah lilitan pada solenoida dalam lilitan

$\mathrm{I}=$ kuat arus listrik dalam ampere (A)

$\mathrm{L}=$ Panjang solenoida dalam meter $(\mathrm{m})$

\section{Gaya Magnetik (Gaya Lorentz)}

Gaya Lorentz menurut Reitz (1993:207) adalah gaya yang ditimbulkan oleh muatan listrik yang bergerak atau oleh arus listrik yang berada dalam suatu medan magnet, B. Arah gaya ini akan mengikuti arah maju skrup yang diputar dari vektor arah gerak muatan listrik (v) ke arah medan magnet, $\mathrm{B}$, seperti yang terlihat dalam rumus berikut: $F=q(v$ $\times B$ ) Dengan $F$ adalah vektor gaya lorentz $(\mathrm{N}), B$ adalah vektor medan magnet $(\mathrm{T}), \mathrm{v}$ adalah vektor kecepatan muatan listrik $(\mathrm{m} / \mathrm{s})$, q adalah besarnya muatan $(\mathrm{C})$. Beberapa keterangan yang dapat kita rumuskan:

1. Gaya tersebut sebanding dengan muatan $\mathrm{q}$. Gaya pada muatan negatif memiliki arah yang berlawanan dengan arah gaya pada muatan positif yang bergerak dengan kecepatan yang sama.

2. Gaya tersebut sebanding dengan kecepatan v.

3. Gaya tersebut tegak lurus terhadap arah medan magnetik maupun kecepatanya. (Tipler, 2001)

$F=q 0 \times E$ dengan qo adalah muatan listrik $(\mathrm{C})$, $E$ adalah kuat medan listrik (N/C). Bila sebuah partikel bermuatan listrik bergerak tegak lurus dengan medan magnet homogen yang mempengaruhi selama geraknya, maka muatan akan bergerak dengan lintasan berupa lingkaran. Sebuah muatan positif bergerak dalam medan magnet B (dengan arah menembus bidang) secara terus menerus akan membentuk lintasan lingkaran dengan gaya Lorentz yang timbul menuju ke pusat lingkaran. Gambar kaidah tangan kanan gaya lorents ditunjukkan pada Gambar 2.2. (Giancoli, 2001).

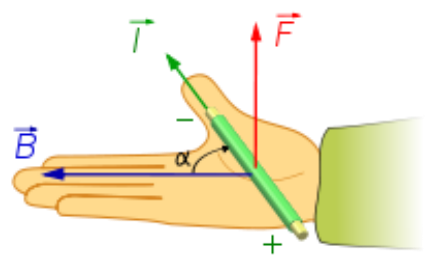

Gambar 2. Kaidah Tangan Kanan Gaya Lorentz

\section{Hukum Lenz}

Apabila ggl induksi dihubungkan dengan suatu rangkaian tertutup dengan hambatan tertentu, maka mengalirlah arus listrik. Arus ini dinamakan dengan arus induksi. Arus induksi dan ggl induksi hanya ada selama perubahan fluks magnetik terjadi. Hukum Lenz menjelaskan mengenai arus induksi, yang berarti bahwa hukum tersebut berlaku hanya kepada rangkaian penghantar yang tertutup. Hukum ini dinyatakan oleh Heinrich Friedrich Lenz (1804 1865), yang sebenarnya merupakan suatu bentuk hukum kekekalan energi.. Hukum Lenz menyatakan bahwa: "ggl induksi selalu membangkitkan arus yang medan magnetnya berlawanan dengan asal perubahan fluks".

\section{PERANCANGAN SISTEM \\ Konfigurasi Sistem}

Dalam system retarder di bagi menjadi dua bagian yaitu rangkaian kontrol dan lilitan, dalam rangkaian kontrol berfungsi sebagai pengatur kuat medan magnet dengan mengatur besaran daya listrik yang masuk dalam lilitan. Sedangkan lilitan berfungsi sebagai konverter dari besaran listrik menjadi besaran kuat medan magnet.

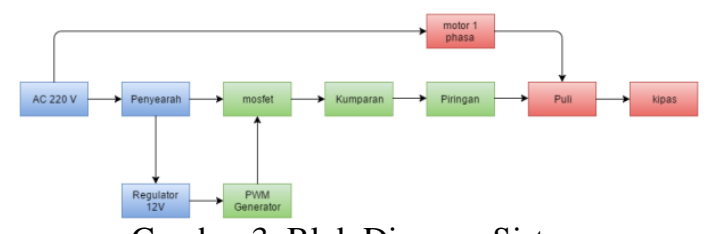

Gambar 3. Blok Diagram Sistem

\section{Rangkaian Kontrol}

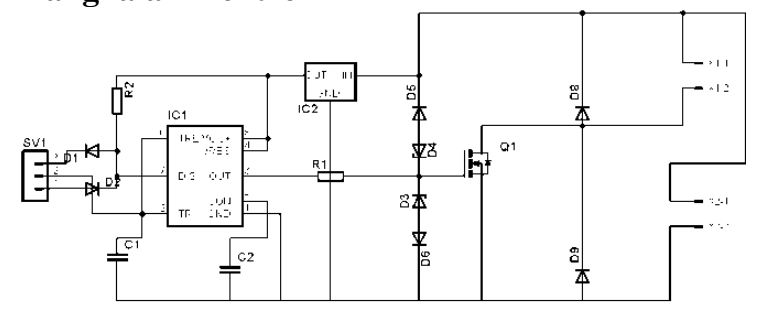

Gambar 4. Rangkaian Kontrol

Rangkaian kontrol adalah pengatur daya yang masuk dalam lilitan dengan mengatur lebar pulsa $P W M$. Dalam rangkaian control ini menggunakan ic 555 sebagai pembangkit frekuensi serta penentu besar kecilnya duty cycle. Rangkaian ini bisa menghasilkan duty cycle dari $1 \%$ sampai $90 \%$ konfigurasi dari kaki 7 dari ic 555 menentukan lebar waktu tunda hidup dan mati. Dan frekuensi osilasi 
dipengaruhi dari kapasitor yang terhubung antara kaki 6 dan 2 dengan ground.

\section{Rangkaian Pembangkit Gelombang}

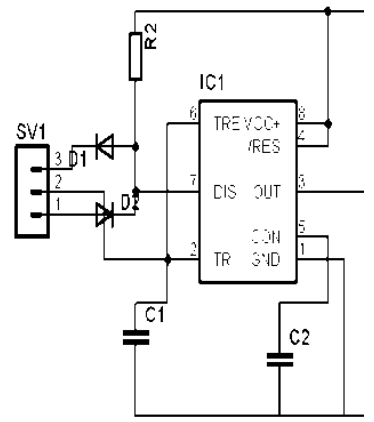

Gambar 5. Rangkaian pembangkit gelombang

Arus jala - jala 220 VAC digunakan sebagai masukan pada rangkaian rectifier untuk disearahkan menjadi arus DC. IC Regulator 7812 berfungsi untuk meregulasi tegangan dari sumber AC, sehingga nilai tegangannya menjadi 12 Volt. Keluaran dari rectifier ini digunakan sebagai sumber tegangan untuk masukan pada IC 555 di PIN 8. Kemudian PIN 2 dan 6 dihubungkan dengan PIN kapasitor agar IC ini berisolasi.

Setelah ic 555 mendapat catu 12 volt, maka PIN 2 dan 6 dihubungkan dengan PIN kapasitor menjadikan ic 555 berosilasi. Lama tunda waktu hidup dan waktu mati ditentukan oleh PIN 7 yaitu discharge dengan konfigurasi antara RA dan RB. RA berupa potensiometer dan RB berupa resistor dengan nilai resistansi $1 \mathrm{~K}$ ohm. Pada ujung-ujung potensiometer diberi diode bolak-balik terhadap Vcc. Hal ini menjadikan ic 555 yang PWM minimalnya $50 \%$ dipaksa untuk bekerja dibawah $50 \%$. Kemudian PIN 3 dihubungkan dengan PIN Gate MOSFET.

\section{Rangkaian Proteksi}

Rangkaian driver merupakan rangkaian output dari mikokontroler Arduino Mega 2560 digunakan untuk memicu tegangan koil pada relai. Rangkaian driver menggunakan IC ULN2803. Gambar 6 merupakan gambar driver relay yang dimaksud.

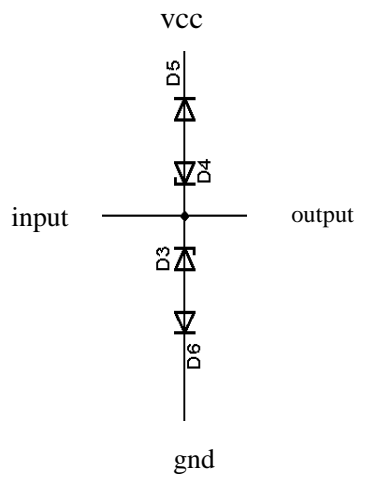

Gambar 6. Rangkaian Proteksi
Rangkaian proteksi ini digunakan untuk memberikan keamanan dari tegangan yang berlebih yang ditimbulkan dari electric statis ataupun tegangan tinggi ESD protection dan High Voltage Protection dimana ESD protection bekerja ketika ada tegangan overshoot diatas 12 Volt maka tegangan lebih dari 12 volt tersebut mengalir melewati zener dan diteruskan ke diode masuk menuju ground. Ketika terjadi gangguan tegangan tinggi dengan periode yang singkat maka aliran listrik tersebut melewati zener 12 Volt lalu dialirkan ke diode menuju ke Vcc.

\section{Rangkaian MOSFET}

MOSFET bekerja ketika diberi gelombang pulse dari IC 555, pada saat gate bernilai positif maka drain dan source akan mengalirkan electron sehingga seolah-olah antara drain dan source terhubung dengan MOSFET kanal N garis bebannya berada di dekat drain. Untuk konfigurasi rangkaian mosfet dapat di lihat pada Gambar 3.5 Ketika ic 555 mengeluakan sinyal low maka Pada daerah Cut-Off MOSFET tidak mendapatkan tegangan input (Vin = $0 \mathrm{~V})$ sehingga tidak ada arus drain Id yang mengalir. Kondisi ini akan membuat tegangan $\mathrm{Vds}=\mathrm{Vdd}$ Dengan beberapa kondisi diatas maka pada daerah cut-off ini MOSFET dikatakan OFF (Full-Off). Kondisi cut-off ini dapat diperoleh dengan menghubungkan jalur input (gate) ke ground, sehingga tidaka ada tegangan input yang masuk ke rangkaian saklar MOSFET dan ketika ic 555 mengeluarkan sinyal high Pada daerah saturasi MOSFET mendapatkan bias input (Vgs) secara maksimum sehingga arus drain pada MOSFET juga akan maksimum dan membuat tegangan $\mathrm{Vds}=0 \mathrm{~V}$. Pada kondisi saturasi ini MOSFET dapat dikatakan dalam kondisi ON secara penuh (Fully-ON).

Pada terminal beban dipasang sebuah diode fast recovery yang dipasang berkebalikan dengan polaritas terminal. Hal ini dimanfaatkan untuk menghilangkan overshoot pada beban induktif.

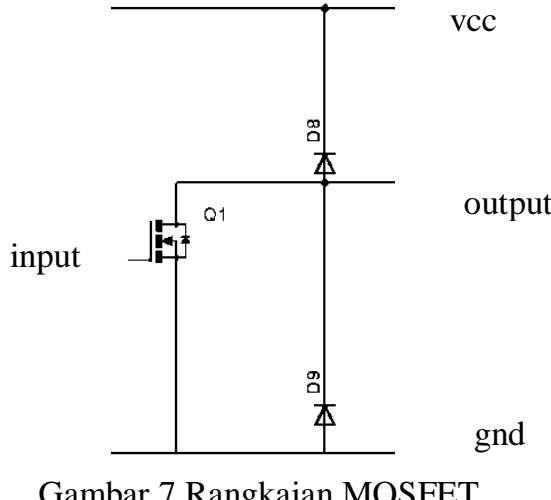

Dalam merancang rangkaian rangkaian elektronika daya, salah satu faktor yang perlu diperhatikan adalah malah kerugian daya yang terjadi pada saklar elektronik yang digunakan. Kerugian daya pada 
saklar elektronik itu sendiri terdiri dari dua bagian yaitu pada kondisi on dan pad kondisi perlihan pada waktu saklar elektronik berkondisi on, kerugian daya terjadi karena adanya drop tegangan pada saklar elektronik yang tengah menghantarkan arus, sehingga efek dari pengalian tegangan terhadap arus tidak dapat dihindarkan pada kondisi peralihan. Dengan adanya dioda ini dapat meredam lonjakan tegangan yang di sebabkan dari pengaruh beban induktor

\section{Lilitan dan piringan konduktor}

Dalam pelambatan komponen ini merupakan komponen yang paling penting. Lilitan yang dibuat dari kawat email dengan diameter kawat 2 millimeter digulung sebanyak 300 kali dengan inti lilitan berbahan feromaknetik mengunakan bahan besi cor dengan ketebalan inti 10 millimeter, panjang lilitan 60 millimeter. Lilitan di susun seri, dengan konfigurasi mekanis 12 lilitan di bagi menjadi 2 bagian, dalam 1 bagian terdiri dari 6 buah lilitan yang disusun dengan kutup yang sama , 2 buah bagian saling mengapit rotor yang berupa konduktor berbahan alumunium.

\section{PENGUKURAN}

\section{Pengukuran Arus Keluaran IC 555}

Hasil pengukuran arus keluaran IC 555 terhadap input Pulse Width Modulation (PWM) ditunjukkan pada tabel 1 .

Tabel 1 Hasil Pengukuran Output Arus Keluaran IC 555

\begin{tabular}{ccc}
\hline No & Arus (A) & PWM $(\%)$ \\
\hline 1 & 0 & 2 \\
2 & 2,5 & 44 \\
3 & 5 & 51 \\
4 & 6 & 64 \\
5 & 7 & 72 \\
6 & 8 & 74 \\
\hline
\end{tabular}

Dari data hasil pengukuran dapat disimpulkan bahwa apabila nilai duty cycle berbanding lurus dengan nilai output arus pada IC 555.

\section{Pengukuran Arus terhadap Arus dan Waktu Pengereman}

Berdasarkan Tabel 1. variasi nilai PWM menghasilkan besar arus yang berbanding lurus, selanjutnya akan dilihat efek variasi tersebut terhadap waktu pengereman. Pengukuran arus pada lilitan bertujuan untuk membandingkan pengaruh keluaran arus dengan waktu pelambatan dari rpm yang di tentukan sampai benda putar berhenti . Hasil pengukuran besar arus keluaran lilitan terhadap waktu pengereman dapat dilihat pada Tabel 2.
Tabel 2. Hasil Perubahan Arus Terhadap Waktu Pengereman

\begin{tabular}{ccc}
\hline No & Arus (A) & Waktu (s) \\
\hline 1 & 0 & 9 '65 \\
2 & 2,5 & 1 '68 \\
3 & 6 & 1 '? \\
4 & 8 & 0 '' \\
\hline
\end{tabular}

Dari hasil pengujian terlihat bahwa besarnya arus keluaran berbanding lurus dengan waktu pengereman.

\section{KESIMPULAN}

Dalam perancangan, percobaan dan pembuatan Rancang Bangun External Electromagnetic Retarders System Pada Motor 1 Phasa, penulis dapat mengambil kesimpulan sebagai berikut:

- Arus pengereman ditentukan oleh duty cycle yang berasal dari rangkaian generator pwm.

- Hubungan arus pengereman dengan waktu pengereman berbanding terbalik jika semakin tinggi arus maka semakin singkat waktu yang dibutuhkan rotor untuk berhenti .

- Tegangan yang masuk pada lilitan berubah rubah sesuai arus yang dilewatkan rangkaian control semakin tinggi arus yang dilewatkan maka tegangan akan turun.

- Hubungan antara arus pengereman dengan arus motor berbanding lurus, dengan menambah arus pengereman akan menambah beban pada motor menyebabkan arus pada motor bertambah.

\section{DAFTAR PUSTAKA}

1. Tipler, P. 2008. Physics for Scientist volume 2. New York : WH Freeman and Company..

2. Ishaq, M. 2007. Fisika Dasar Elektisitas dan Magnetisme. Yogyakarta: Graha Ilmu.

3. Millman, Halkias, M.Barmawi, dan M.O.Tjia. 1971. Integrated Electronics:Analog and Digital Circuits and Systems. Jakarta : Erlangga.

4. Ramdhani, Mohamad. 2008. Rangkaian Listrik. Jakarta : Erlangga.

5. Bishop, Owen. 2004. Dasar-Dasar Elektronika. Jakarta : Erlangga.

6. Halliday, David. Robert Resnick. 1978. Fisika Jilid II Edisi Ketiga. Jakarta : Erlangga 